\title{
PENGARUH MODEL PEMBELAJARAN KOOPERATIF TIPE SCRAMBLE TERHADAP PRESTASI BELAJAR SISWA DI SMKN 1 PANJALU
}

\author{
Gianugrah Syahyana $^{1)}$, Muhmamad Taufiq ${ }^{2)}$, Alfadl Habibie ${ }^{3)}$ \\ ${ }^{1,2,3)}$ Pendidikan Teknologi Informasi FKIP Universitas Muhammadiyah Tasikmalaya \\ e-mail: Gianusyh@gmail.com
}

\begin{abstract}
Abstraksi
Penelitian ini bertujuan untuk mengetahui pengaruh model pembelajaran kooperatif tipe scramble terhadap hasil prestasi belajar siswa kelas X pada materi tipe data(pemgrograman dasar) di SMKN 1 Panjalu. Penelitian ini menggunakan metode eksperimen dan jenis penelitian yang digunakan quasi experimental design dengan bentuk nonequivalent group pretest posttest design. Populasinya adalah seluruh siswa kelas X TKJ SMKN 1 Panjalu. Sampel dalam penelitian ini adalah kelas X TKJ 1 yang berjumlah 36 siswa sebagai kelas eksperimen dan kelas X TKJ 2 yang berjumlah 34 siswa sebagai Kelas control. Data hasil belajar siswa dikumpulkan menggunakan test, soal pretest dan posttest. Data yang diperoleh dianalisis menggunakan SPSS 22.0. Hasil penelitian ini menunjukan bahwa terdapat perbedaan yang signifikan antara hasil belajar siswa yang menggunakan model pembelajaran kooperatif tipe scramble dengan hasil belajar siswa yang menggunakan model pembelajaran konvensional pada mata pelajaran Pemrograman Dasar materi tipe data. Dari hasil pengolahan dan analisis data terdapat informasi mengenai perbedaan hasil belajar siswa yang menggunakan model konvensional (kelas control) dengan yang menggunakan model pembelajaran kooperatif tipe scramble (kelas eksperimen). Hal ini terbukti pada rata-rata posttest kelas control dan rata-rata posttest kelas eksperimen. Ratarata posttest kelas control 68.02 dengan kategori tinggi dan rata-rata posttest kelas eksperimen 76.58 dengan kategori sangat tinggi. Uji hipotesis yang sebelumnya dilakukan uji normalitas dan uji homogenitas terlebih dahulu. Dari hasil analisis diketahui data berdistribusi normal dan homogen serta diperoleh nilai signifikan (2tailed) sebesar 0.000. Nilai signifikan 0.000 tersebut lebih kecil dibandingkan dengan taraf signifikan 0.05. Hasil analisis data tersebut menunjukan adanya perbedaan yang signifikan antara prestasi belajar siswa kelas kontrol dan eksperimen. Hal ini menunjukan model pembelajaran kooperatif tipe scramble berpengaruh terhadap prestasi belajar siswa pada materi tipe data mata pelajaran pemrograman dasar kelas X TKJ 1 di SMKN 1 Panjalu.
\end{abstract}

Kata Kunci: Model Pembelajaran Kooperatif tipe Scramble, Prestasi Belajar Siswa, Pembelajaran Pemrograman Dasar

\begin{abstract}
This study aims to determine The Influence of Scramble Type Cooperative Learning Model on Class X Student Learning Achievement in Data Type Material (basic programming) in SMK 1 Panjalu. This study uses an experimental method and the type of research used is quasi experimental design in the form of nonequivalent group pretest posttest design. The population is all grade X students of TKJ 1 Panjalu Vocational School. The sample in this study was class X TKJ 1, amounting to 36 students as an experimental class and class X TKJ 2, totaling 34 students as a control class. Student learning outcomes data were collected using tests, pretest and posttest questions. The data obtained were analyzed using SPSS 22.0. The results of this study indicate that there is a significant difference between student learning outcomes using scramble type cooperative learning models and student learning outcomes using conventional learning models in Basic Programming subjects data type material. From the results of data processing and analysis there is information about the differences in student learning outcomes using conventional models (control classes) with those using scramble type cooperative learning models (experimental classes). This is evident in the average posttest of the control class and the average posttest of the experimental class. The average posttest of the control class is 68.02 with a high category and the average posttest of the experimental class is 76.58 with a very high category. Hypothesis testing previously carried out the normality test and homogeneity test first. From the analysis results it is known that the data is normally distributed and homogeneous and obtained a significant value (2-tailed) of 0,000. The significant value of 0.000 is smaller than the significant level of 0.05. The results of the data analysis showed a significant difference between the learning achievement of the control and experimental class students. This shows that the scramble type
\end{abstract}


cooperative learning model has an influence on student achievement in the data type of basic programming subjects in class X TKJ 1 in SMK 1 Panjalu.

Keywords: Scramble type Cooperative Learning Model, Student Learning, Achievement, Basic Programming Learning

\section{Pendahuluan}

Pendidikan merupakan suatu kegiatan yang membuat manusia itu bertanggung jawab dan termasuk faktor yang sangat penting bagi kehidupan manusia untuk mengembangkan kegiatan belajar mengajar yang berkualitas. Tujuan pendidikan adalah menyediakan lingkungan yang memungkinkan siswa untuk mengembangkan bakat dan kemampuan secara optimal, sehingga siswa dapat membentuk karakter diri dan berfungsi sepenuhnya, serta sesuai dengan kebutuhan pribadi dan kebutuhan lingkungannya.

Guru harus memberikan suntikan dalam bentuk strategi dalam kegiatan pembelajaran, sehingga dengan bantuan itu anak didik dapat mengetahui materi pembelajaran yang telah diajarkan dan mencapai prestasi belajar yang baik.

Dari hasil wawancara kepada salah satu guru kelas X Jurusan Teknik Komputer dan Jaringan (TKJ) Sekolah Menengah Kejuruan (SMK) Negeri 1 Panjalu yang bernama Gilang Bayu Perdana menunjukan bahwa kegiatan belajar mengajar belum optimal, karena sebagian siswa kurang aktif dan tidak mampu menguasai materi tipe data sehingga pretasi belajar siswa rendah serta guru masih menerapkan metode ceramah dalam pembelajaran, dimana siswa hanya sebagai pendengar sehingga kurang melibatkan aktivitas siswa secara langsung sehingga prestasi belajar di kelas X TKJ SMKN 1 Panjalu rendah atau kurang dari 70 atau kurang dari KKM (Kriteria Ketuntasan Minimal).

Menurut beberapa para ahli dalam Djamarah (2017: 20-21) menyatakan bahwa "prestasi adalah hasil dari suatu kegiatan. Dimana hasil yang dimaksud adalah hasil yang memiliki ukuran atau nilai" [1].

Sebuah pembelajaran akan terlaksana dengan baik dan menempuh tujuan yang telah direncanakan agar prestasi belajar naik, maka guru harus mampu merencanakan sebuah pembelajaran sedemikian baiknya dari mulai materi yang akan diajarkan, tujuan dari pembelajaran, kegiatan yang akan dilakukan selama pembelajaran, metode, model dan media yang akan digunakan oleh guru selama pembelajaran.

Setiap siswa memiliki perbedaan dalam mendapatkan informasi atau materi yang akan digunakan, maka dari itu guru harus mampu membuat strategi pembelajaran agar setiap siswa mencapai tujuan pembelajaran yang telah direncanakan sesuai dengan aturan yang berlaku. Guru tidak hanya pandai dalam penguasaan materi saja, akan tetapi guru juga harus mampu mengelola kelas agar terjadinya pembelajaran yang aktif antara pengajar dengan siswa.

Berdasarkan pengalaman peneliti, betapa pentingnya pemilihan model-model pembelajaran yang sesuai dengan pembelajaran khususnya mata pelajaran pemrograman dasar materi tipe data di jenjang Pendidikan Sekolah Menengah Kejuruan (SMK). Dalam hal ini penerapan model pembelajaran kooperatif scramble sesuai untuk digunakan [2].

Istilah scramble berasal dari Bahasa Inggris yang diterjemahkan dalam Bahasa Indonesia berarti perbuatan pertarungan dan perjuangan. Scramble merupakan model pembelajaran yang mengajak siswa untuk menemukan jawaban dan menyelesaikan permasalahan yang ada dengan cara membagikan lembar soal dan lembar jawaban yang disertai dengan alternatif jawaban yang tersedia. Model pembelajaran scramble akan disesuaikan dengan materi yang akan disampaikan kepada siswa untuk menemukan jawaban dan menyelesaikan permasalahan yang ada dengan cara membagikan lembar soal dan lembar jawaban yang disertai dengan alternatif jawaban yang tersedia dalam suasana yang menyenangkan.

Mengacu pada hal tersebut peneliti termotivasi untuk mengadakan penelitian guna mengetahui pengaruh prestasi belajar siswa pada mata pelajaran pemrograman dasar materi tipe data yang dilaksanakan di kelas $\mathrm{X}$ jurusan Teknik Komputer dan Jaringan (TKJ) SMKN 1 Panjalu menggunakan metode penelitian eksperimen. Sehingga judul penelitian yang diangkat oleh penulis yaitu "Pengaruh Model Pembelajaran Kooperatif Tipe Scramble Terhadap Prestasi Belajar Siswa Kelas X Pada Materi Tipe Data" yang akan dilakukan di SMKN 1 Panjalu. Adapun kelas yang dijadikan kelas eksperimen yaitu kelas X TKJ 1 dan yang dijadikan kelas kontrol yaitu kelas X TKJ 2 dengan menggunakna teknik random sampling.

Dari latar belakang yang telah dijabarkan di atas, maka rumusan masalah: "Bagaimanakah pengaruh model pembelajaran kooperatif tipe scramble terhadap prestasi belajar siswa kelas X pada materi tipe data di SMKN 1 Panjalu?". Tujuan dari penelitian ini yaitu diharapkan dapat meningkatkan prestasi siswa pada materi tipe data mata pelajaran pemrograman dasar di SMKN 1 Panjalu kelas X.

Joyce dan Weil dalam Maolani (2017: 53) menyatakan "model pembelajaran adalah suatu rencana atau pola yang digunakan dalam menyusun kurikulum, mengatur materi, pelajaran dan memberi petunjuk" kepada pengajar 
dikelas dalam setting pengajaran maupun setting lainnya [3]. Adapun model pembelajaran kooperatif merupakan rangkaian pembelajaran yang dilakukan oleh siswa dalam kelompok-kelompok tertentu untuk mencapai tujuan pembelajaran yang telah dirumuskan. Salah satu model dari model pembelajaran kelompok adalah model pembelajaran kooperatif. Bern dan Erickson dalam Komalasari (2013 : 62) menyatakan "pembelajaraan kooperatif merupakan strategi pembelajaran yang mengorganisir pembelajaran dengan menggunakan kelompok belajar kecil dimana siswa bekerja bersama untuk mencapai tujuan pembelajaran" [4].

Menurut Shoimin [2] dalam melakukan model pembelajaran kooperatif tipe scramble ada beberapa langkah yang harus dilakukan oleh pendidik dalam pembelajaran di kelas. Adapun langkah-langkah model pembelajaran kooperatif tipe scramble yaitu:

1) Persiapan

Pada tahap ini guru menyiapkan bahan dan media yang akan digunakan dalam pembelajaran. Media yang digunakan berupa kartu soal dan kartu jawaban yang sebelumnya jawaban telah diacak. Guru menyiapkan kartu-kartu sebanyak kelompok yang telah dibagi. Guru mengatur hal-hal yang mendukung proses belajar mengajar, misalnya mengatur tempat duduk sesuai kelompok yang telah dibagi ataupun memeriksa kesiapan siswa belajar.

2) Kegiatan inti

Kegiatan dalam tahap ini adalah setiap masing-masing kelompok melakukan diskusi untuk mengerjakan soal dan mencari kartu soal untuk jawaban yang cocok. Sebelumnya jawaban telah diacak sedemikian rupa. Guru melakukan diskusi kelompok untuk menganalisis dan mendengar pertanggung jawaban dari setiap kelompok atas hasil kerja yang telah disepakati dalam masing-masing kelompok kemudian membandingkan dan mengkaji jawaban yang tepat dan logis.

3) Tindak lanjut

Kegiatan tindak lanjut tergantung dari keaktifan siswa saat proses pembelajaran. Maka dari itu tindak lanjutnya adalah kegiatan berupa pemberian tugas dan kegiatan menyempurnakan susunan teks asli, jika terdapat susunan yang tidak logis.

Shoimin mengungkapkan bahwa model pembelajaran kooperatif tipe scramble terdapat kelebihan dan kekurangan. Adapun kelebihannya [2] yaitu a) Setiap anggota kelompok dalam teknik ini setiap siswa tidak ada yang diam karena setiap individu diberi tanggung jawab akan keberhasilan kelompoknya b) Model pembelajaran ini memungkinkan siswa untuk saling belajar sambal bermain. Mereka dapat berkreasi sekaligus belajar dan berpikir, mempelajari sesuatu secara santai dan tidak membuat mereka stres atau tertekan c) Selain membangkitkan kegembiraan dan melatih keterampilan tertentu metode scramble juga dapat memupuk rasa solidaritas dalam kelompok d) Materi yang diberikan melalui salah satu metode permainan biasanya mengesankan dan sulit untuk dilupakan e) Metode ini dapat mendorong siswa berlomba-lomba untuk maju. Kekurangannya yaitu a) Pembelajaran ini terkadang sulit dalam merencakannya, karena terbentur dengan kebiasaan siswa dalam belajar b) Terkadang dalam mengimplementasikannya, memerlukan waktu yang Panjang sehingga guru sulit menyesuaikan dengan waktu yang telah ditentukan c) Selama kriteria keberhasilan belajar ditentukan oleh siswa menguasai materi pelajaran, sehingga pembelajaran sulit diimplementasikan guru.

\section{Metode Penelitian}

Metode penelitian yang digunakan dalam penelitian ini adalah metode eksperimen. Menurut Sugiyono [5], metode penelitan eksperimen diartikan sebagai metode penelitian yang digunakan untuk mencari pengaruh perlakuan tertentu terhadap yang lain dalam kondisi yang terkendalikan. Metode ini sebagai bagian dari metode kuantitatif mempunyai ciri khas tersendiri, terutama dengan dengan adanya kelompok kontrolnya. Dengan kata lain bahwa penelitian meggunakan pendekatan kuantitatif karena menggunakan data dan statistik.

Jenis penelitian yang digunakan adalah quasi experimental design dan desain yang digunakan adalah nonequivalent group pretest. Dimana dalam desain ini terdapat dua kelompok yang masing-masing dipilih secara random. Pengukuran dilakukan 1 kali treatment, karena sesuai dengan banyaknya materi yang akan diajarkan. Dimana sebelum diberi perlakuan kelompok diberi pretest, dengan maksud untuk mengetahui kesetabilan dan kejelasan kelompok sebelum diberi perlakuan.

$$
\begin{aligned}
& \mathrm{NR}_{1} \mathrm{O}_{1} \times \mathrm{O}_{2} \\
& \mathrm{NR}_{2} \mathrm{O}_{3} \mathrm{O}_{4}
\end{aligned}
$$

\section{Rumus Nonequivalent Group Pretest Posttest Design}

$$
\text { (Sumber: Sugiyono 2016, 107) }
$$

Keterangan:

$N R_{1} \quad=$ Kelompok eksperimen tidak dipilih secara random/acak

$N R_{2} \quad=$ Kelompok kontrol tidak dipilih secara random/acak

$\mathrm{O}_{1} \& \mathrm{O}_{3}=$ Pretest (kelompok eksperimen tidak dipilih secara random/acak) 


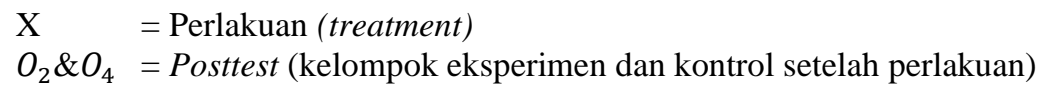

Tempat penelitian yang akan digunakan oleh peneliti yaitu di Kelas X jurusan TKJ SMKN 1 Panjalu yang beralamat di Jln Raya Sukamantri, Dsn. Hujung Tiwu, Kec. Panjalu, Kab. Ciamis. Populasi yang digunakan dalam penelitian ini yaitu seluruh siswa kelas X SMKN 1 Panjalu yang berjumlah 70 siswa. Sampel yang digunakan yaitu siswa kelas X TKJ 1 yang terdiri dari 18 orang laki-laki, 18 orang perempuan, dan siswa kelas X TKJ 2 yang terdiri dari 24 orang laki-laki dan 10 orang perempuan. Untuk menentukan kelas eksperimen dan kelas kontrol, peneliti menggunakan teknik random sampling. Populasi yang dijadikan kelas eksperimen yaitu kelas X TKJ 1 dan yang dijadikan kelas kontrol yaitu kelas X TKJ 2.

Teknik pengumpulan data berkenaan dengan cara-cara yang digunakan untuk mengumpulkan data dalam penelitian ini cara-cara yang digunakan untuk mengumpulkan data yaitu dengan melakukan dokumentasi, wawancara, dan tes. Dokumetasi digunakan sebagai alat bukti dan data yang akurat mengenai keterangan yang ada disekolah. Pada teknik wawancara peneliti menggunaan wawancara terstruktur dan tidak terstruktur. Wawancara tidak terstruktur adalah wawancara bebas dimana peneliti belum mengetahui secara pasti informasi yang akan diperoleh dan tidak menggunakan pedoman wawancara, dokumen atau pertanyaan yang sudah disiapkan tersususun secara lengkap untuk pengumpulan data, teknik wawancara ini dilakukan sebelum peneliti menggunakan teknik wawancara terstruktur. Dan yang terakhir adalah tes, tes yang dilakukan untuk mengumpulkan data tentang prestasi belajar siswa yaitu membuat kisi-kisi soal, menyusun soal tes, mengadakan uji coba, dan menganalisis hasil dari uji coba. Soal yang digunakan dalam penelitian ini adalah soal yang berisi pertanyaan-pertanyaan disertai dengan pilihan jawaban untuk pertanyaan-pertanyaan tersebut. Jawaban-jawaban yang disediakan bagi setiap pertanyaan sesuai dengan materi yang diberikan.

Peneliti menggunakan soal pilihan ganda pada materi tipe data. Instrumen yang digunakan yaitu test, test diberikan kepada kelas kontrol dan kelas eksperimen berupa soal pretest dan posttest. Dengan soal yang sama, sesuai dengan materi di kompetensi dasar dan indikator pencapaian siswa khusus mata pelajaran pemgrograman dasar.

Soal tes pada penelitian ini berjumlah 15 butir soal, yang dipilih dari 20 soal setelah pengujian validitas dan reliabilitas. tes yang dilakukan untuk mengumpulkan data tentang prestasi belajar siswa yaitu membuat kisi-kisi soal, menyusun soal tes, mengadakan uji coba, dan menganalisis hasil dari uji coba. Soal yang digunakan dalam penelitian ini adalah soal yang berisi pertanyaan-pertanyaan disertai dengan pilihan jawaban untuk pertanyaanpertanyaan tersebut. Jawaban-jawaban yang disediakan bagi setiap pertanyaan sesuai dengan materi yang diberikan.

Peneliti menggunakan soal pilihan ganda pada materi tipe data. Instrumen yang digunakan yaitu test, test diberikan kepada kelas kontrol dan kelas eksperimen berupa soal pretest dan posttest. Dengan soal yang sama, sesuai dengan materi di kompetensi dasar dan indikator pencapaian siswa khusus mata pelajaran pemgrograman dasar. Soal tes pada penelitian ini berjumlah 15 butir soal, yang dipilih dari 20 soal setelah pengujian validitas dan reliabilitas.

\section{Hasil Dan Pembahasan}

Deskripsi data menggambarkan tentang data-data dari penelitian yang telah dikumpulkan. Data yang dikumpulkan berasal dari hasil nilai Posttest kelas X TKJ 1 dan X TKJ 2. Dimana kelas X TKJ 1 sebagai kelompok eksperimen yang menggunakan model pembelajaran Kooperatif tipe Scramble dan kelas X TKJ 2 sebagai kelompok kontrol yang menggunakan mode pembelajaran konvensional. Setelah data diperoleh maka peneliti menganalisis data dengan melakukan uji prasyarat yaitu uji normalitas dan uji homogenitas dan uji hipotesis untuk mengetahui pengaruh dari penggunaan model pembelajaran Kooperatif tipe Scramble.

Diketahui bahwa nilai rata-rata pretest kelas eksperimen sebesar 50.64 sedangkan kelas kontrol 46.65. Kemudian setelah melakukan pretest, dilakukan posttest. Nilai rata-rata posttest kelas eksperimen yaitu 76.58 sedangkan nilai rata-rata posttest kelas kontrol 68.03 sangat berbeda nilai rata-rata posttest dengan kelas eksperimen.

Uji normalitas digunakan untuk mengetahui data berasal dari populasi yang berdistribusi normal atau tidak. Hasil data posttest diuji menggunakan Uji Normalitas Shapiro-Wilk pada SPSS 22.0. Dasar pengambilan keputusan uji Normalitas Shapiro-wilk yaitu jika nilai Sig. > 0.05 maka data berdistribusi normal dan jika nilai Sig. $<0.05$ maka data tidak berdistribusi normal.

Adapun hasil dari uji normalitas shapiro-wilk untuk kelas eksperiman adalah 0.078>0.05 dan kelas kontrol $0.053>0.05$ ini menunjukkan bahwa populasi data yang diperoleh berdistribusi normal.

Uji homogenitas dilakukan untuk mengetahui variansi dari kedua populasi. Peneliti menguji variansi nilai hasil belajar dari kelas eksperimen dan kontrol. Pengujian dilakukan pada SPSS 22.0. Hasil keputusan uji homogenitas yaitu nilai Sig $>0.05$.

Adapun hasil uji homogenitas dari kelas eksperimen dan kelas kontrol adalah $0.185>0.05$ ini menunjukkan bahwa kedua kelas memiliki varian nilai yang sama atau homogen. Uji hipotesis dilakukan setelah uji prasayarat 
yakni uji normalitas dan uji homogenitas terpenuhi. Uji hipotesis yang digunakan adalah uji-t pada SPSS 22.0. Uji-t digunakan untuk mengetahui pengaruh hasil belajar siswa kelas eksperimen yang menggunakan model pembelajaran take and give dengan prestasi belajar siswa kelas kontrol yang menggunakan model pembelajaran konvensional. Keputusan diambil berdasarkan pada ketentuan uji hipotesis, yaitu nilai Sig.(2-tailed) $>0.05$, maka Ho diterima dan Ha ditolak, atau sebaliknya nilai Sig.(2-tailed) < 0.05, maka Ho ditolak dan Ha diterima. Adapun hasil Uji Hipotesis Beda Rata (T-tes) dari kedua kelas adalah $0.000<0,05$. Sesuai dengan Sig. (2-tailed) yang dihasilkan maka dinyatakan bahwa Ho ditolak dan Ha diterima. Sehingga dapat disimpulkan bahwa model pembelajaran Kooperatif tipe Scramble berpengaruh terhadap prestasi belajar siswa kelas X TKJ 1 dan 2 pada materi tipe data mata pelajaran pemrograman dasar di SMKN 1 Panjalu.

Dengan demikian dapat disimpulkan bahwa terdapat pengaruh yang signifikan dalam menggunakan Model Pembelajaran Kooperatif tipe Scramble Terhadap Prestasi Belajar Siswa Kelas X Pada Materi tipe data (pemrograman dasar),

\section{Kesimpulan}

Berdasarkan hasil analisis, temuan dan pembahasan mengenai Pengaruh Model Pembelajaran Kooperatif tipe Scramble Terhadap Prestasi Belajar Siswa Kelas X Pada Materi tipe data (pemrograman dasar), diperoleh kesimpulan sebagai berikut:

1. Prestasi belajar siswa dengan menggunakan model pembelajaran kooperatif tipe scramble pada materi tipe data mengalami peningkatan. Dimana nilai rata-rata pretest sebeleum perlakuan dengan kategori rendah. Sedangkan rilai rata-rata posttest setelah diberikan perlakuan dengan kategori yang sangat tinggi.

2. Terdapat pengaruh model pembelajaran kooperatif tipe scramble pembelajaran Kooperatif tipe Scramble terhadap prestasi belajar siswa pada materi tipe data di SMKN 1 panjalu. Hal ini berdasarkan dari hasil analisis diketahui data berdistribusi normal dan homogen serta diperoleh nilai signifikan (2-tailed) sebesar 0.000. Nilai signifikan 0.000 tersebut lebih kecil dibandingkan dengan taraf signifikan 0.05.dengan membandingkan prestasi belajar siswa kelas eksperimen yang menggunakan model pembelajaran kooperatif tipe scramble dengan prestasi belajar siswa di kelas kontrol dengan tanpa model kooperatif tipe scramble, dimana Ho ditolak karena signifikansi dari kedua kelompok tersebut < 0,05 dan Ha diterima. Dengan demikian dapat disimpulkan bahwa pembelajaran dengan menggunakan model pembelajaran kooperatif tipe scramble berpengaruh terhadap prestasi belajar siswa pada materi tipe data mata pelajaran pemrograman dasar kelas X TKJ 1 di SMKN 1 Panjalu.

\section{Daftar Pustaka}

[1] S. B. Djamrah, Prestasi Belajar dan Kompetensi Guru, Surabaya: Usaha Nasional, 2017.

[2] A. Shoimin, Model Pembelajaran Inovatif dalam Kurikulum 2013, Yogyakarta: Ar-Ruzz Media, 2014.

[3] I. Maolani, Strategi Pembelajaran, Yogyakarta: PT Leutika Nouvalitera, 2017.

[4] K. Komalasari, Pembelajaran Kontekstual, Bandung: Refika Aditama, 2013.

[5] Sugiyono, Metode Penelitian, Bandung: Alfabeta, 2016.

[6] G. Syahyana, " Pengaruh Model Pembelajaran Kooperatif Tipe Scramble Terhadap Prestasi Belajar Siswa Di Smkn 1 Panjalu", Skripsi, Prodi Pendidikan Teknologi Informasi, Universitas Muhammadiyah Tasikmalaya, Tasikmalaya, Jabar, 2019.

\section{Biodata Penulis}

Gianugrah Syahyana lahir 21 tahun silam di ciamis tepatnya pada tanggal 04 Juni 1998, memperoleh gelar Sarjana Pendidikan (S.Pd) Program Studi Pendidikan Teknologi Informasi FKIP Universitas Muhammadiyah Tasikmalaya, lulus tahun 2019. 